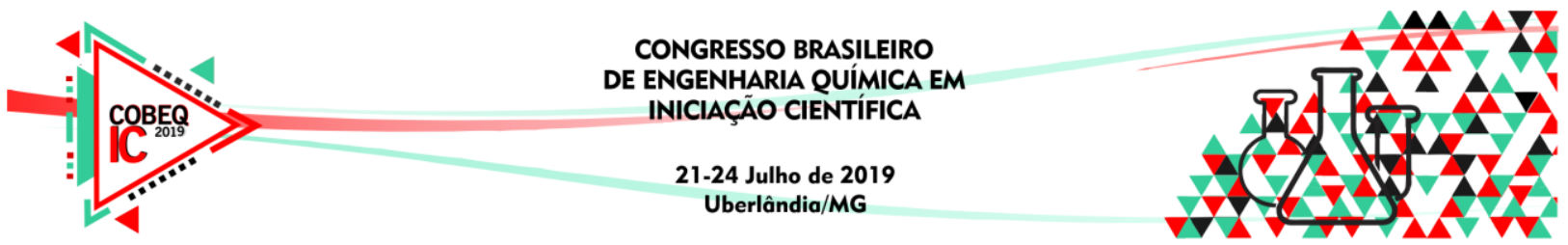

\title{
MODIFICAÇÃO DE SUPORTES DE POLI (ÁCIDO LÁCTICO) OBTIDOS POR IMPRESSORA 3D PARA IMOBILIZAÇÃO DE
} LIPASE DE RHIZOPUS ORYZAE

\author{
B. F. IZIDORO ${ }^{1}$, V. T. MAZZIERO ${ }^{1}$, M. O. CERRI ${ }^{1}$, R. F. C. MARQUES ${ }^{2}$, A. V. DE \\ PAULA $^{1}$ \\ ${ }^{1}$ Universidade Estadual Paulista, Departamento de Bioprocessos e Biotecnologia \\ ${ }^{2}$ Universidade Estadual Paulista, Departamento de Físico-química \\ E-mail para contato: barbara_izidoro@hotmail.com, ariela@fcfar.unesp.br
}

RESUMO - Atualmente, o poli (ácido lático) é um políéster que vêm sendo amplamente utilizado na confecção de objetos sólidos tridimensionais com dimensões e estruturas desejadas. Nesse contexto, esta pesquisa visou imprimir, em impressora 3D, suportes de PLA para imobilização da lipase de Rhizopus oryzae por ligação covalente. Para isso, foi preciso incorporar aos suportes, grupos amino livres para a ligação da lipase, determinando-se as melhores condições para o processo de imobilização enzimática. Em seguida, realizou-se o teste de ninidrina e análise de ressonância magnética nuclear (RMN) para confirmar a incorporação desses grupos. Observou-se que o suporte submetido a 2 horas de reação de aminólise, teve sua estrutura comprometida. No teste de ninidrina, verificou-se que a melhor condição para a reação de aminólise seria 15 minutos de reação e $60 \mathrm{mg} / \mathrm{ml}$ de hexametilenodiamina. Além disso, a análise de RMN confirmou a incorporação dos grupos amino, através do surgimento de picos nas regiões dos prótons $-\mathrm{CH}_{3}$ e $-\mathrm{CH}$ do lactilo hidroxilado, em 1,51 1,52 (a) e 4,40 4,36 ppm (b), e dos prótons $\mathrm{C}_{2} \mathrm{H}_{4}$ da hexametilenodiamina, em 4,07 4,03 ppm (e) no PLA modificado. Ademais, verificou-se a maior atividade hidrolitica para o derivado imobilizado triturado, modificado com $1 \%$ de glutaraldeído $(90,9640$ e $61,6024 \mathrm{U} / \mathrm{g})$.

\section{INTRODUÇÃO}

O poli (ácido lático) ou PLA é um poliéster alifático e semicristalino com alto potencial para substituir polímeros de origem petroquímica. Apresenta alta resistência, além ser o primeiro polímero a ser produzido a partir de recursos não tóxicos e renováveis. Esse polímero apresenta diversas aplicações, desde a manufatura de embalagens, até a fabricação de protótipos ou dispositivos médicos bioabsorvíveis. Além disso, por ser um material termoplástico e de fácil processamento, pode ser aplicado em impressora 3D na produção de diferentes tipos de peças moldadas (FARAH et al., 2016).

Uma impressora 3D é um equipamento utilizado para transformar filamentos termoplásticos (como o PLA) em objetos sólidos 3D, projetados em programa CAD. Para isso, uma bobina é acionada e o filamento lá contido é desenrolado e aquecido por um bico extrusor. $O$ termoplástico será fundindo sobre a mesa da impressora, numa deposição de camada sobre camada, até a completa impressão da peça desejada (BESKO et al., 2017). 


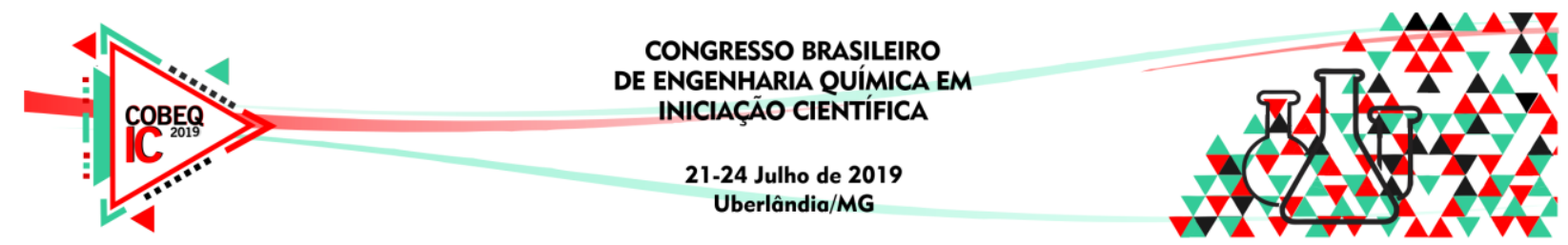

Essa tecnologia tem como principal vantagem a diminuição de desperdícios, consumo de matérias-primas e de energia, além de não emitir resíduos, ruídos, ou substâncias tóxicas durante o processo de impressão. Ademais, pode ser aplicada na impressão de objetos como capas para celulares e peças de automóveis, até órgãos humanos com células vivas e na confecção de matrizes para imobilização enzimática (PORTO, 2016)

Nesse contexto, o presente projeto teve por objetivo imprimir, em impressora 3D, diferentes suportes de PLA e empregá-los como suporte para imobilização de lipase. Para isso, os suportes foram modificados a fim de possibilitar a ligação covalente da enzima em sua superfície. Através da reação entre os grupos éster do PLA e os grupos amino da hexano diamina foram produzidos grupos amino livres $\left(\mathrm{PLA}-\mathrm{NH}_{2}\right)$ aos quais a lipase irá se ligar.

\section{METODOLOGIA}

\subsection{Impressão 3D}

Os suportes de poli (ácido láctico), desenhados em programa CAD e impressos em impressora 3D, foram projetados a fim de maximizar a superfície de contato entre enzima e suporte, através da elaboração de pequenos poros ao longo de toda a extensão do mesmo.

\subsection{Reação de Aminólise}

Para incorporação de grupamentos amina nos suportes de PLA empregou-se a metodologia descrita por ZHU et al., (2004) com adaptações a fim de determinar as melhores condições para a reação de aminólise. Para isso, realizaram-se diferentes sínteses, com três amostras cada, na primeira, os tempos de reação empregados foram de 5,8 e 15 min e na segunda síntese e 15,45 min e 2 horas, sendo que a concentração de hexametilenodiamina testada foi de 6 e $60 \mathrm{mg} / \mathrm{ml}$, para ambas as sínteses.

\subsection{Teste de Ninidrina}

A fim de confirmar a incorporação dos grupamentos amina no suporte de PLA, este foi imerso em solução de ninidrina $0,5 \mathrm{mg} / \mathrm{ml}$, durante 5 minutos de fervura, para detecção de aminas primárias, a partir do aparecimento da coloração roxa no suporte.

\subsection{Teste RMN}

A análise de ressonância magnética nuclear, proposta por LAVERTU et al., (2003), com modificações quanto às concentrações dos reagentes e o polímero utilizado foi empregada na caracterização do suporte modificado.

\subsection{Ativação do Suporte para imobilização por ligação covalente}

Para obtenção do suporte ativado com glutaraldeído empregou-se a metodologia descrita por BASSAN et al., (2016). Para verificar a influência do aumento da superfície de contato no processo de imobilização da enzima, uma parte dos suportes foi triturada em liquidificador. Além disso, variou-se a concentração de glutaraldeído em 1\% e 10\%. 


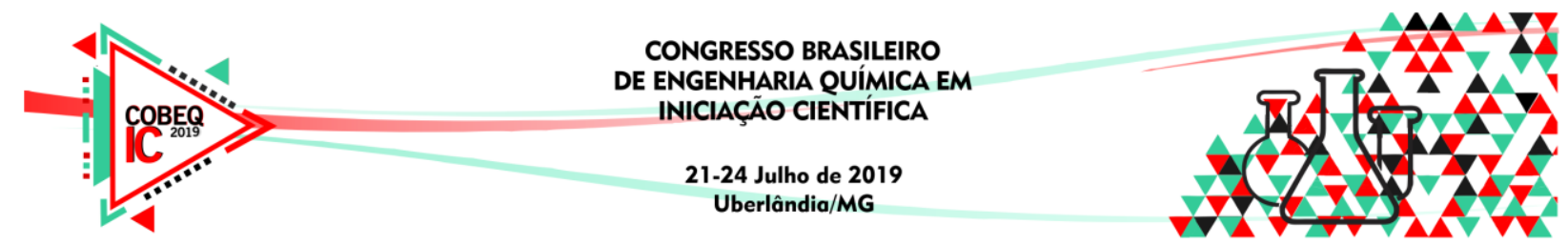

\subsection{Imobilização dos Suportes Ativados com Glutaraldeído}

Para cada grama seca de suporte ativado, foram adicionados $20 \mathrm{~mL}$ de solução de lipase $(25 \mathrm{mg} / \mathrm{mL})$ em tampão fosfato $0,1 \mathrm{~mol} / \mathrm{L} \mathrm{e} \mathrm{pH} 7$. Os suportes foram mantidos sob agitação suave, em agitador magnético, por 24 horas para a imobilização da lipase Rhizopus oryzae.

\subsection{Atividade Hidrolítica do Derivado Imobilizado}

A atividade hidrolítica foi determinada pelo método de retrotitulação descrito por PAULA (2012).

\section{RESULTADOS E DISCUSSÕES}

\subsection{Impressão 3D}

A figura 1 apresenta o desenho do suporte em programa CAD, com suas dimensões representadas por cotas, e uma imagem tirada após sua impressão em impressora 3D.

Figura 1 - Representação do suporte de PLA projetado em CAD com suas dimensões expressas por cotas (a). Imagem dos suportes impressos em impressora 3D (b)

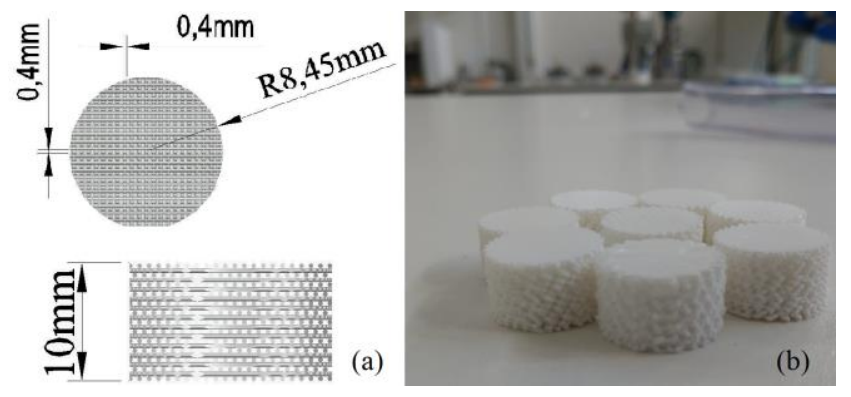

\subsection{Reação de aminólise e teste de Ninidrina}

Após as reações de aminólise no suporte de PLA, verificou-se que os suportes mantidos à $55^{\circ}$ durante o tempo de reação de 2 horas tiveram sua estrutura prejudicada. As amostras restantes foram imersas em solução de ninidrina para confirmar a presença de grupamentos amina. A partir da figura 2, verificou-se que a maior quantidade de grupamentos amina, foi a amostra de maior concentração $(60 \mathrm{mg} / \mathrm{ml})$ e tempo de reação (15 minutos).

Figura 2 - Aparecimento de coloração roxa nos suportes de PLA modificados.

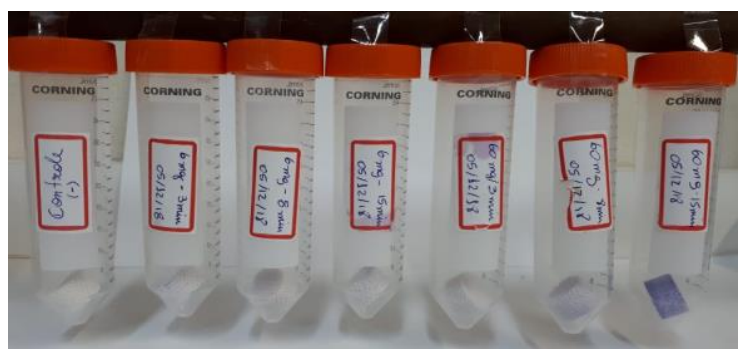




\subsection{Teste RMN}

O mecanismo da reação de aminólise realizado neste trabalho é apresentado na Figura 3 a seguir.

Figura 3 - Mecanismo da reação de aminólise no poli (ácido láctico) com hexametilenodiamina (YU et al, 2018).

Poly(lactic acid) (PLA)<smiles>CC(O)C(=O)OC(C)C(=O)OCC(C)C(=O)OCC(C)C(=O)O</smiles>

hexametilenodiamina: $\mathrm{H}_{2} \mathrm{~N}$<smiles>CCCCCCCN</smiles><smiles>CC(O)C(=O)OC(C)C(N)(C(=O)O)C(=O)OC(C)C(=O)O</smiles><smiles>[Te][Te]</smiles>

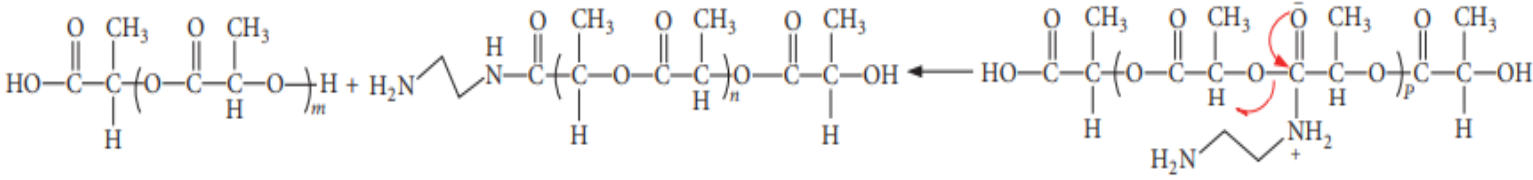

A caracterização dos suportes por RMN apresentou sinais distintos. A figura 4 a seguir apresenta os principais picos obtidos para os suportes de PLA não modificado (branco) e modificados em 15 e 45 minutos de reação.

Figura 4 - Região dos picos obtidos pela análise de RMN para o PLA não modificado e modificado (15 e $45 \mathrm{~min}$ ). Fonte: autor.
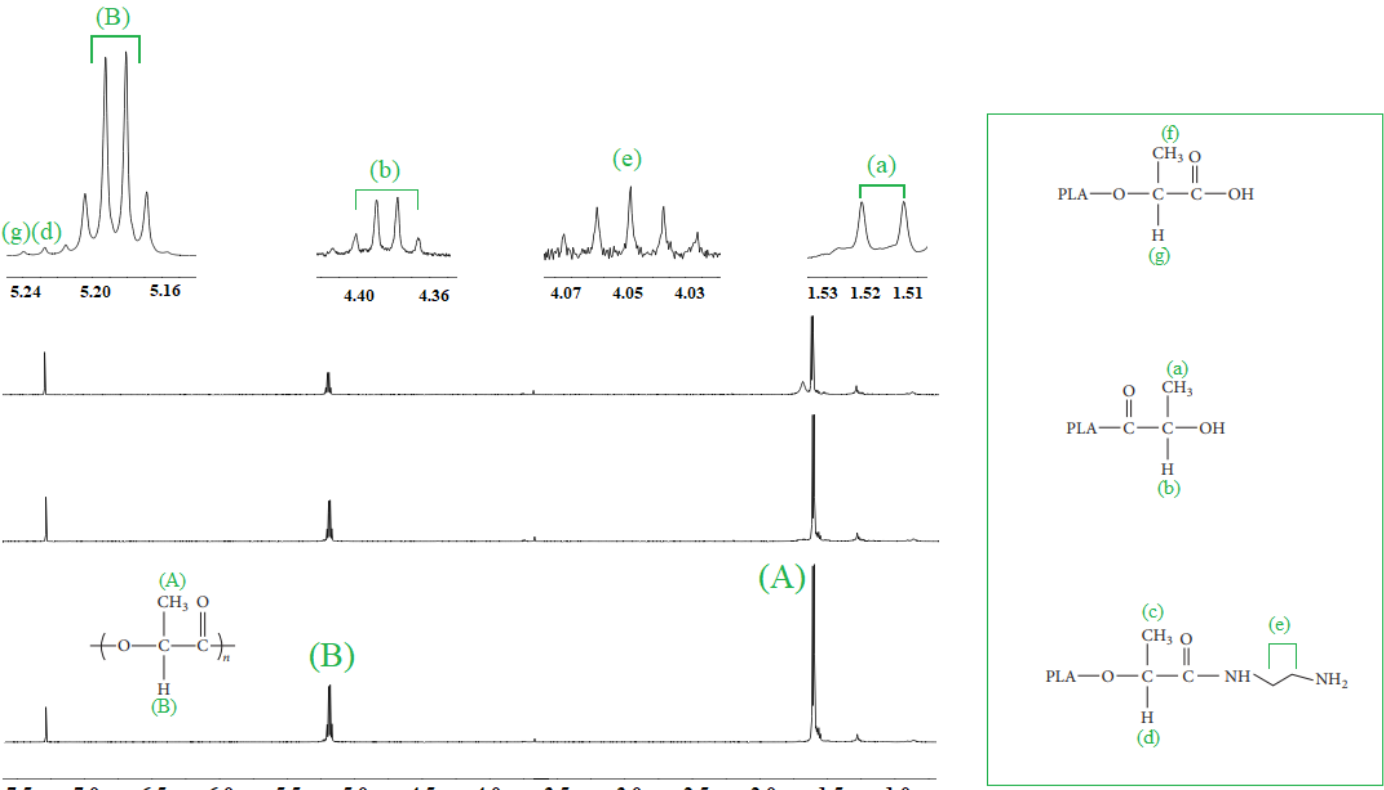

$7.5 \quad 7.0$

$6.5 \quad 6.0$

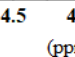




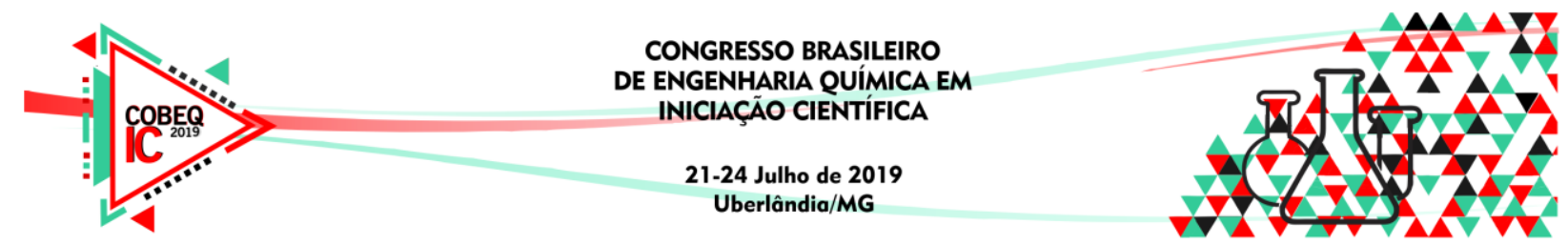

Verificaram-se sinais na faixa de 1,60 1,61 (A) e 5,17 5,20 ppm (B), referentes aos prótons $-\mathrm{CH}_{3}$ e $-\mathrm{CH}$ do PLA. Após a modificação, surgiram novos picos, de 1,51 1,52 (a) e 4,40 4,36 ppm (b), pertencentes aos prótons $-\mathrm{CH}_{3}$ e $-\mathrm{CH}$ do lactilo hidroxilado. Picos em 5,23 (d) e 1,61 ppm (c) atribuídos a $-\mathrm{CH}$ e $-\mathrm{CH}_{3}$ conectados à hexametilenodiamina. Além disso, picos dos prótons $\mathrm{C}_{2} \mathrm{H}_{4}$ da hexametilenodiamina aparecem em 4,07 4,03 ppm (e) e do - $\mathrm{CH}$ e $-\mathrm{CH}_{3}$ do lactilo carboxilado, em 5,25 (g) e 1,54 ppm (f). Neste contexto, Yu et al. (2018), visando sintetizar copolímeros a partir de PLA aminolisado, obteve picos em regiões muito semelhantes ao desta pesquisa. Assim, os resultados obtidos na análise de RMN confirmaram a proposta do mecanismo de aminólise representado na figura 3.

\subsection{Atividade Hidrolítica do Derivado Imobilizado}

Os valores de atividade obtidos para os suportes, peça e pó, imobilizados com a lipase de Rhizopus oryzae são apresentados na tabela 1 a seguir.

Tabela 1 - Valores de atividade hidrolítica obtidos para o PLA na forma de peça e triturado.

\begin{tabular}{|c|c|c|}
\hline Suporte & $\begin{array}{c}\text { Atividade amostra 1 } \\
(\mathrm{U} / \mathrm{g})\end{array}$ & $\begin{array}{c}\text { Atividade amostra 2 } \\
(\mathrm{U} / \mathrm{g})\end{array}$ \\
\hline \hline Peça PLA - 1\% glutaraldeído & 25,0336 & - \\
\hline Peça PLA- 10\% glutaraldeído & 17,6786 & - \\
\hline PLA pó - 1\% glutaraldeído & 90,9640 & 61,6024 \\
\hline PLA pó - 10\% glutaraldeído & 20,4734 & 10,1665 \\
\hline
\end{tabular}

Verificaram-se maiores valores de atividade para o suporte triturado com $1 \%$ de glutaraldeído. Júnior (2007), ao variar a concentração de glutaraldeído de 1 a 10\%, na imobilização da lipase de Candida antarctica, obteve resultados próximos aos deste trabalho, com atividade máxima na concentração de $3 \%$ do reagente. Isso se deve à alta reatividade do glutaraldeído, que, em grandes concentrações, gera distorções no sítio ativo da enzima e má orientação da mesma durante a imobilização (MENDES, 2009).

\section{CONCLUSÃO}

A partir da variação de parâmetros durante o processo de modificação e do teste de ninidrina realizado com os suportes de PLA, foram estabelecidas, como as melhores condições para a reação de aminólise, o tempo de 15 minutos de reação empregando uma concentração igual a $60 \mathrm{mg} / \mathrm{ml}$ de hexametilenodiamina. Além disso, tanto o teste de ninidrina quanto a análise de RMN confirmaram a incorporação dos grupamentos amina na superfície do PLA, indispensáveis para a imobilização da lipase. Ademais, concluiu-se a maior atividade obtida foi para o PLA triturado e ativado com $1 \%$ de glutaraldeído.

\section{AGRADECIMENTOS}

Agradecimentos à Fundação de Amparo à Pesquisa do Estado de São Paulo, FAPESP (Processo 2017/11482-7). 


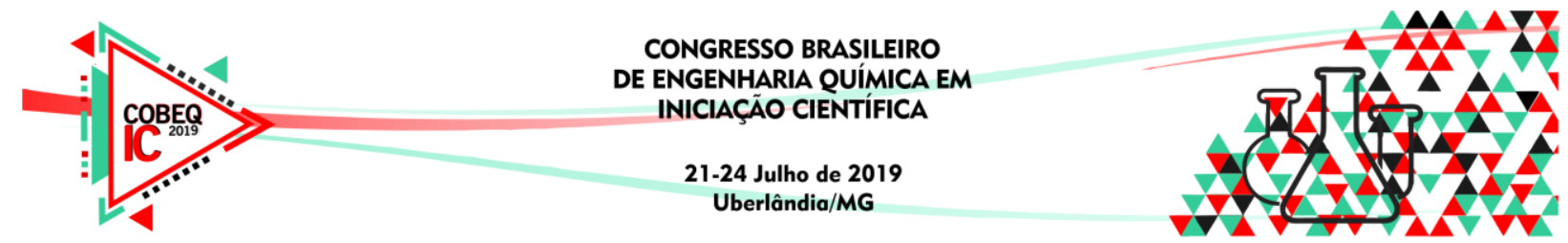

\section{REFERÊNCIAS}

BASSAN, C. J.; SOUZA, B. M. T.; PEIXOTO, G.; CRUZ, P. Z. C.; GALÁN, M. P, J.; VAZ, S. B. A.; GARRIDO, S.S.; FILICE, M.; MONTI, R. Immobilization of trypsin in lignocellulosic waste material to produce peptides with bioactive potencial from whey protein. Materials, v. 9, n. 5, 2016.

BESKO, M.; BILYK, C.; SIEBEN, P. G. Aspectos técnicos e nocivos dos principais filamentos usados em impressão 3D. Gestão, Tecnologia e Inovação, v. 01, p. 9-18, 2017.

FARAH, S.; ANDERSON, D. G.; LANGER, R. Physical and Mechanical Properties of PLA, and Their Functions in Widespread Applications- A Comprehensive Review. Advanced Drug Delivery Reviews, v. 107, p. 367-92, 2016.

JÚNIOR, A. C. imobilização de lipase de candida antarctica b em quitosana para obtenção de biodiesel por transesterificação do óleo de mamona. 2007. 107 f. Dissertação (Mestre em Engenharia Química) - Engenharia Química, Universidade Federal de Santa Catarina, Florianópolis/SC. 2007.

LAVERTU, M.; XIA, Z.; SERREQI, A. N.; BERRADA, M.; RODRIGUES, A.; WANG, D.; BUSCHMANN, M. D.; GUPTA. A validated $1 H$ NMR method for the determination of the degree of deacetylation of chitosan. Journal of Pharmaceutical and Biomedical Analysis. 2003.

MENDES, A. A. Seleção de suportes e protocolo de imobilização de lipase para síntese enzimática de biodiesel. 2009. 194 f. Dissertação (Mestrado em Engenharia Química) Engenharia Química, Universidade Federal de São Carlos, São Carlos. 2009.

PAULA, A. V. Reestruturação da gordura de leite por interesterificação enzimática empregando lipase imobilizada: otimização das condições reacionais e operacionais. 2011. 212 f. Tese (Doutorado em Ciências) - Escola de Engenharia de Lorena, Universidade de São Paulo, Lorena/SP, 2012.

YU, W.; ZHU, L.; SHI, J.; ZHAO, C. Synthesis of Poly(lactic acid)-block-poly(N,Ndimethylaminoethyl methacrylate) Copolymers with Controllable Block Structures via Reversible Addition Fragmentation Polymerization from Aminolyzed Poly(lactic acid). International Journal of Polymer Science. 2018.

ZHU, Y.; GAO, C.; LIU, Y.; SHEN, J. Endothelial cell functions in vitro cultured on poly(Llactic acid) membranes modified with different methods. Journal of Biomedical Materials Research. 2004. 